\title{
Flood Flow Modeling in a River System Using Adaptive Neuro-Fuzzy Inference System
}

\author{
Nazrin Ullah (Corresponding author) \\ Research scholar, Department of Civil Engineering, NIT Silchar, Assam, PIN: 788010, India \\ Tel: 90-8522-8262Ｅ-mail: nazrinullah@gmail.com \\ Parthasarathi Choudhury \\ Professor, Department of Civil Engineering, NIT Silchar, Assam, PIN: 788010, India Tel: \\ 94-3537-2651 E-mail:ps_chou@yahoo.com
}

Received: May 22, 2013 Accepted: June 14, 2013

doi:10.5296/emsd.v2i2.3738

URL: http://dx.doi.org/10.5296/emsd.v2i2.3738

\begin{abstract}
This paper presents the application of a data-driven model, Adaptive Neuro-Fuzzy Inference System (ANFIS) in forecasting flood flow in a river system. ANFIS uses neural network algorithms and fuzzy reasoning to map an input space to an output space. In the present study, ANFIS models are used to forecast common downstream flow rates and flow depths in a river system having multiple inflows. Three different ANFIS model forms: (i) depth-depth $(\mathrm{H}-\mathrm{H})$ model, (ii) depth-discharge (H-Q) model and (iii) discharge-discharge (Q-Q) models are considered in this study. The models are used for forecasting one-hour ahead common downstream flow rates and flow depths in a river system based on past upstream flows. The flow and flow depths data are divided arbitrarily into different categories $(2,3,4,6)$ and different number of membership functions (Triangular, Gaussian, Trapezoidal and Bell) selecting two categories with Gaussian input and constant output membership functions based on trial and error. Performances of the ANFIS model with selected categories and membership functions are tested and verified by applying a time-series model, Autoregressive Integrated Moving Average (ARIMA) to the same river system. ARIMA has been successfully used in time-series forecasting leading to satisfactory performances. A further validation of the ANFIS model has been done by applying it to another river basin, Tar River Basin in USA. The results evaluated on the basis of standard statistical criteria showed improved performances by the ANFIS depth-depth forecasting models. The results also indicate that performances of the ANFIS models with multiple inflows are more satisfactory and closely follow performances of the ARIMA models. The study demonstrates applications of the multiple inflows ANFIS models in forecasting downstream flood flow and flow depth in a river system.
\end{abstract}

Keywords: ANFIS, ARIMA, flow depth, discharge 


\section{Introduction}

Flood movement modeling serves as a cost effective means for minimizing the damages caused by flooding. Study of the flood movements and developing flood forecasting and warning systems are essential to provide assistance against the possible flood losses. Various hydrological models are available in the literature to study flood movement in river reaches which can be categorized as Conceptual, Physical, Stochastic and Data-driven models. Conceptual models are generally based on Saint-Venant equations comprising of partial differential equations of continuity and momentum. In the past few decades, many conceptual based models have been proposed for forecasting hydrological phenomena (Chau and Lee, 1991 a, b, Wagener et al., 2001, Kitanidis and Bras, 2010). While these models can well explain the internal mechanisms of the hydrological processes but require large amount of calibration data, sophisticated mathematical tools and expertise with the model. Physical models are based on understanding of the physical processes; often require pertaining physical data sets and may not be ideal for real-time forecasting due to tremendous data requirements and associated long computation time for model calibration. Applications of physically based models can be found in the works of Feyen et al. (2000), Rosenberg et al. (2011).

Data-driven models on the other hand, extract information from the input - output data sets without considering the complex physical process by which they are related and establish a statistical correspondence between input(s) and output(s). Data driven models such as Adaptive Neuro-Fuzzy Inference System (ANFIS), Artificial Neural Network (ANN) and Fuzzy Logic (FL) have been found to be potentially useful in modeling time-series hydrologic problems. The main advantage of these models is that they do not require specifying functional relationships apriori; self organize their structure and adapt it in an interactive manner learning the underlying relationship(s). Data driven models are preferable for flood forecasting problems where usually the main concern is to make accurate and timely forecast essential for flood damage mitigation. In the hydrological forecasting context, application of data-driven models can be found in the works of Dawson and Wilby (1998); Tokar and Johnson (1999); Liong et al. (2000); Bazartseren et al. (2003) and Chen et al. (2006) among others. Karl and Lohani (2010) developed a flood forecasting system using statistical and ANN techniques in the downstream catchment of Mahanadi basin, India and found that ANN methods perform better than the statistical methods. Jacquin and Shamseldin (2006) explored the application of Takagi-Sugeno fuzzy inference systems to rainfall-runoff modeling. They showed that fuzzy inference systems are a suitable alternative to the traditional methods for modeling the non-linear relationship between rainfall and runoff. Nayak et al (2005) carried out a study on river flow forecasting on the basis of rainfall and runoff data using ANN, FL, ANFIS and reported better performances by the ANFIS model. The ANFIS model works on a set of linguistic rules, can handle imprecision and uncertainty present in the model and the data structure. Chidthong et al (2009) developed a hybrid multi-model to forecast the flood level at Chiang Mai and the Koriyama flood in Japan; found satisfactory application of the applied model. Hydrologic events being essentially time-dependent, a number of time-series models have also been used to model hydrologic problems. Traditionally, time-series models have been used for modeling and forecasting water resource hydrological systems because such models are accepted as a standard representation of a stochastic time-series (Maier and 
Dandy, 1997). Applications of time series models such as, Autoregressive Moving Average (ARMA), Autoregressive Integrated Moving Average (ARIMA) in hydrology can be found in the works of Box and Jenkins, 1976; Masmoudi and Habaieb, 1993; Martins et al., 2011. An ARIMA model is a generalization of an ARMA model; it makes time-series stationary in both calibration and forecasting phases. One of the recent investigations that evaluate performances of ARIMA and ARMA models in forecasting Dez dam reservoir located in Teleh Zang Station can be found in Valipour et al (2012). The author reported improved performances by the ARIMA model as compared to ARMA model. There is considerable volume of literatures on the applications of ARIMA and ARMA models in forecasting hydrologic time series. Extensive application of these models in hydrology is mainly due to the fact that these models have the capability of generating new sequences of time-series having same statistical parameters with the observed series. However, such models do not attempt to represent the non-linear dynamics inherent in the transformation of rainfall to runoff and therefore may not always perform well (Hsu et al., 1995).

Study of the literature pertaining to the applications of data-driven models in forecasting river flows show that most of the models use a single upstream flow depth/flow rate to simulate and forecast downstream flow depth/flow rates in a river reach. In real world, a number of tributaries join the main channel to form a river system. To forecast downstream flows in a river system accurately, inclusion of all past upstream flows in the model is essential. In the present study ANFIS models that use past flow information for several upstream stations are used to forecast common downstream outflow in a river system. To forecast common downstream outflow, three ANFIS models are considered: (i) depth-depth (H-H) model, (ii) depth-discharge (H-Q) model and (iii) discharge-discharge (Q-Q) model. The models are applied to a river system in Barak basin, India obtaining forecasts for the common downstream flow rates and flow depths for the river system. Performances of the ANFIS models are tested and verified by applying ARIMA model to the same river system. Flow rate and flow depth forecasts obtained by applying ARIMA models are compared with the results of the ANFIS models. Results obtained indicate better performances by the H-H ANFIS model and it is also found that ANFIS model results closely follow the ARIMA model. Applicability of the multiple inflows ANFIS model in forecasting common downstream discharge is further tested by using it in Tar River Basin, USA.

\section{Models}

\subsection{ANFIS Model}

ANFIS is an artificial intelligence technique that has been successfully used for mapping input-output relationship based on available data sets (Jang et al., 1997; El-Shafie et al., 2007). It is based on the first order Sugeno-fuzzy inference system proposed by Jang, 1993 and it uses neural network learning algorithms and fuzzy reasoning to map an input space to an output space. With the ability to combine the numeric power of a neural system with the verbal power of a fuzzy system, ANFIS has been found to be powerful in modeling numerous processes. The model works on a set of linguistic rules developed using expert knowledge. The fuzzy rule base of the ANFIS model is set up by combining all categories of variables. For example, if there are $\mathrm{n}$ inputs and if each input is divided into c categories then there will 
be $c^{n}$ rules. For 3 upstream flows in a river system represented by the inputs $\mathrm{x}, \mathrm{y}$ and $\mathrm{z}$ having 2 categories namely low flow and high flow each, there would be 8 rules in the rule base; the output for each rule is written as a linear combination of input variables and a constant term. Part of the rule sets can be illustrated as follows:

Rule 1: If $x$ is low, $y$ is low and $z$ is low, then the output $o_{1,1,1}=a_{1} x+b_{1} y+c_{1} z+d_{1}$;

Rule 2: If $x$ is low, $y$ is low and $z$ is high, then the output $o_{1,1,2}=a_{2} x+b_{2} y+c_{2} z+d_{2}$

Rule 3: If $x$ is low, $y$ is high and $z$ is high, then the output $o_{1,2,2}=a_{3} x+b_{3} y+c_{3} z+d_{3}$

Rule 8: If $x$ is high, $y$ is high and $z$ is high, then the output $o_{2,2,2}=a_{8} x+b_{8} y+c_{8} z+d_{8}$

The coefficients $a(..) ; b(..) ; c(..) ; d(.$.$) are parameters of the output functions and these$ parameters are determined through training.

For each of the rules triggered, memberships of the inputs variables $\mathrm{x}, \mathrm{y}, \mathrm{z}$ are estimated through learning. The result of T-norm gives the weight to be assigned to the corresponding output. Finally, outputs from all triggered rules are combined to give a single weighted average output given by,

$$
O=\frac{\sum w_{i, j, k} o_{i, j, k}}{\sum w_{i, j, k}}
$$

Here, $i, j, k$ are the input categories. $O_{i, j, k}=$ output due to rule $i, j, k$ and $w_{i, j, k}=$ is the associated weight for rule $i, j, k$

In order to develop a fuzzy inference model for forecasting, parameters that define the shape of the membership functions are identified by the back-propagation learning algorithm, whereas the parameters in the output function $(a(..) ; b(..) ; c(..) ; d(.)$.$) are determined by least$ square type method. The model possesses features of both neural networks and fuzzy control system such as learning abilities, optimization abilities and human-like "if-then" rule thinking. The framework of ANFIS is shown in Fig.1.

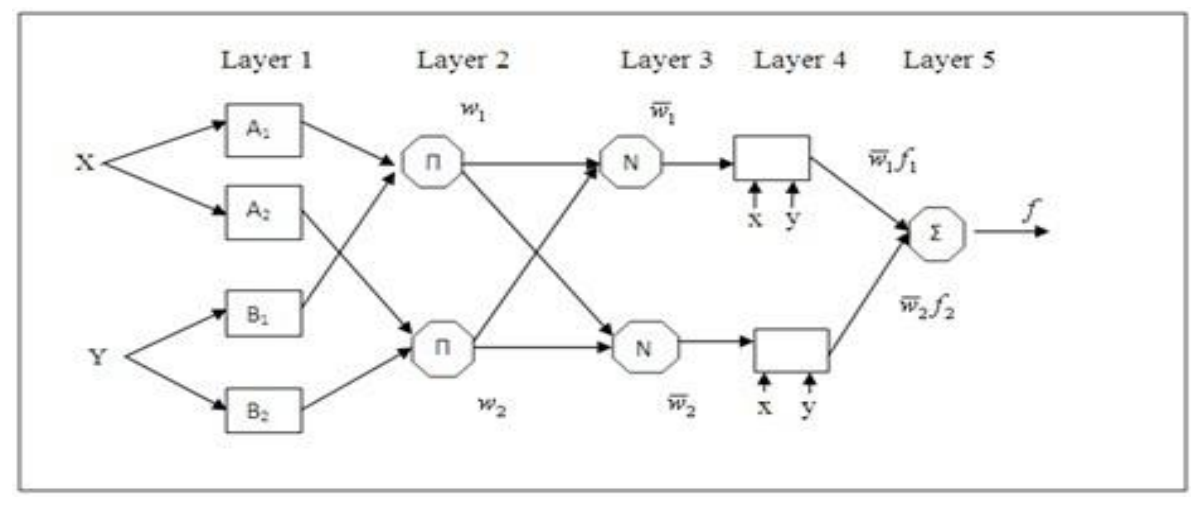

Figure 1. Framework of ANFIS 


\section{Macrothink}

\subsection{ARIMA Model}

ARIMA model is a general time-series model for forecasting popularized by Box and Jenkins (1976). ARIMA model is fitted to time-series data to better understand the data and to predict future points in the series. It uses three components for modeling the serial correlation in the time-series data. The first component (l) is the autoregressive term (AR), the second component (d) is the integration (I) order term. Each integration order corresponds to differencing the time series. I (d) represents differencing the data' $d$ ' times and the third component $(\mathrm{q})$ is the moving average (MA) term. The general form of the ARIMA model (l, $d$ and $\mathrm{q})$ is given by:

$$
y_{t}=a_{0}+a_{i} y_{t-i}+\ldots+b_{j} \varepsilon_{t-j}
$$

Where, $i=1,2,3 \ldots l$ and $j=1,2,3 \ldots q . y_{t}$ is a stationary stochastic process and has a non zero average. $a_{0}$ is a constant coefficient, $a_{\bar{i}}$ represents autoregressive coefficient and $b_{j}$ represents moving average coefficients and $e_{\tilde{i}}$ is the white noise disturbance term.

Selected ARIMA model with optimal parameters are used for forecasting the depth and discharge time series. The most adequate model is selected on the basis of statistical criteria such as Bayesian Information Criterion (BIC) and Coefficient of determination $\left(\mathrm{R}^{2}\right)$. These statistical criteria determine if an ARIMA model with a specific set of $1, d$ and q parameters is a good statistical fit. The $\mathrm{R}^{2}$ is defined as:

$$
R^{2}=1-\left(\frac{n-1}{n-p}\right) \frac{S S E}{S S T}
$$

where $n$ and $p$ are the number of observations and the number of regression parameters. SSE and SST are the sum of squared errors and the total sum of squares, respectively. BIC is defined as:

$$
B I C=n \ln \left(\frac{S S E}{n}\right)+p \ln (n)
$$

For a given data set, a number of candidate models having different $1, \mathrm{~d}$ and q parameters may be fitted and the model giving lowest values for BIC and maximum $\mathrm{R}^{2}$ can be selected as the best model.

\section{Study Area and Data Set}

Flood forecasting using ANFIS and ARIMA models is made to a river network in Barak basin in India. The Barak River is the second largest river in the North-eastern regions of India and rises in the state of Nagaland at an elevation of approximately 2,300 meters. The drainage area of the River is $14,500 \mathrm{~km}^{2}$ approximately. Barak valley is having a population of about 


\section{Macrothink}

2.98 million. The basin is situated on the route of south-west monsoon; it receives an annual rainfall of 2500-4000mm having 80-85\% from Mid-April to Mid-October. The problem of flood is very complex and acute in the valley. During monsoon it receives 2-3 flood waves almost every year, inundating vast part of the valley and causing widespread damages. Agriculture being the main occupation of about $70-75 \%$ of the population in the valley, the problem of recurrent flood jeopardizes economic growth and development in the region.

In this study, a river network bounded by three upstream inflow gauging stations and a downstream outflow gauging station in the main river Barak is selected for application of the ANFIS and ARIMA models. Details of the study area along with the river system are shown in Fig.2(a). The upstream gauging stations are located at Phulertal in the main river Barak, Tulargram in the tributary Sonai and at Matijuri in the tributary Katakhal. Applying the models, flow depth/discharge at the common downstream station, Badarpurghat is predicted using known flow depths/discharges at the upstream stations Phulertal, Tulargram and at Matijuri in the river system. Hourly discharge and flow depth data for all gauging stations in the study area during monsoon season were collected from Central Water Commission (CWC), Shillong. A total of 9864 datasets of the monsoon period in the year 2003-2005 have been used in the study. $75 \%$ of the dataset are used for training and cross validation while the rest $25 \%$ are used for testing the model performances. To validate the ANFIS model, the model is also applied to a river system in Tar River Basin, USA.

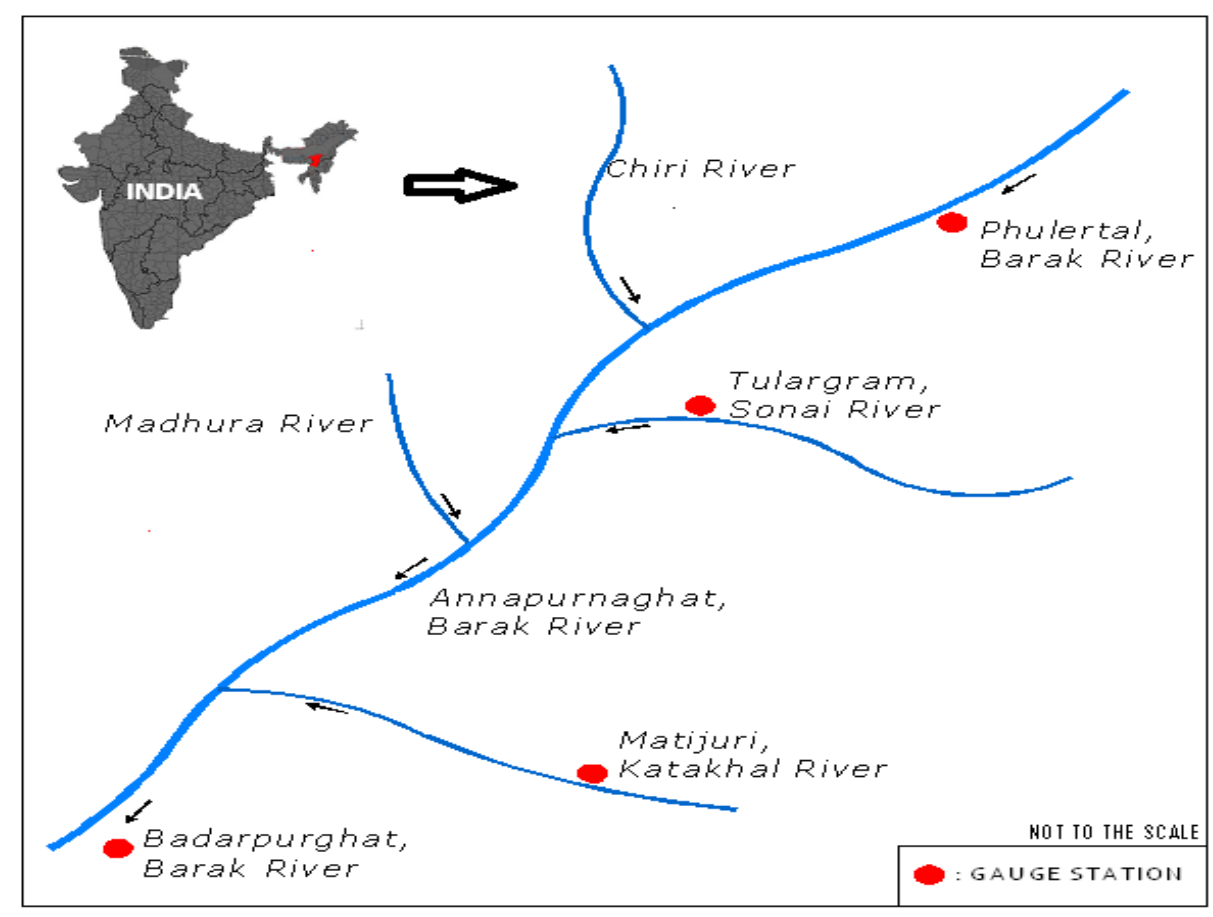

Figure 2 (a). Barak River and its tributaries

The Tar-Pamlico River basin has a drainage area of $13921 \mathrm{Km}^{2}$ and is one of the four river basins that entirely lie within the state of North Carolina (NC) in the US. Major tributaries of the Tar River main stem include Cokey Swamp, and Fishing, Swift and Sandy creeks. In the Upper Tar River Basin, tributary flow from Sweeft creek, Fishing and Little fish creek 
contribute to the flow at Tarboro, NC and at Greenville, $\mathrm{NC}$ a further downstream point in the river system. Figure 2(b) shows the map of the Tar River Basin. This study uses flow information for the gauge sites, Rocky Mount, Hilliardson, Enfield and Tarboro to forecast flow at the downstream station, Tarboro applying the ANFIS model. Data sets having 2-hour interval was prepared from the flood period data series and used for analyzing the river network flood events.

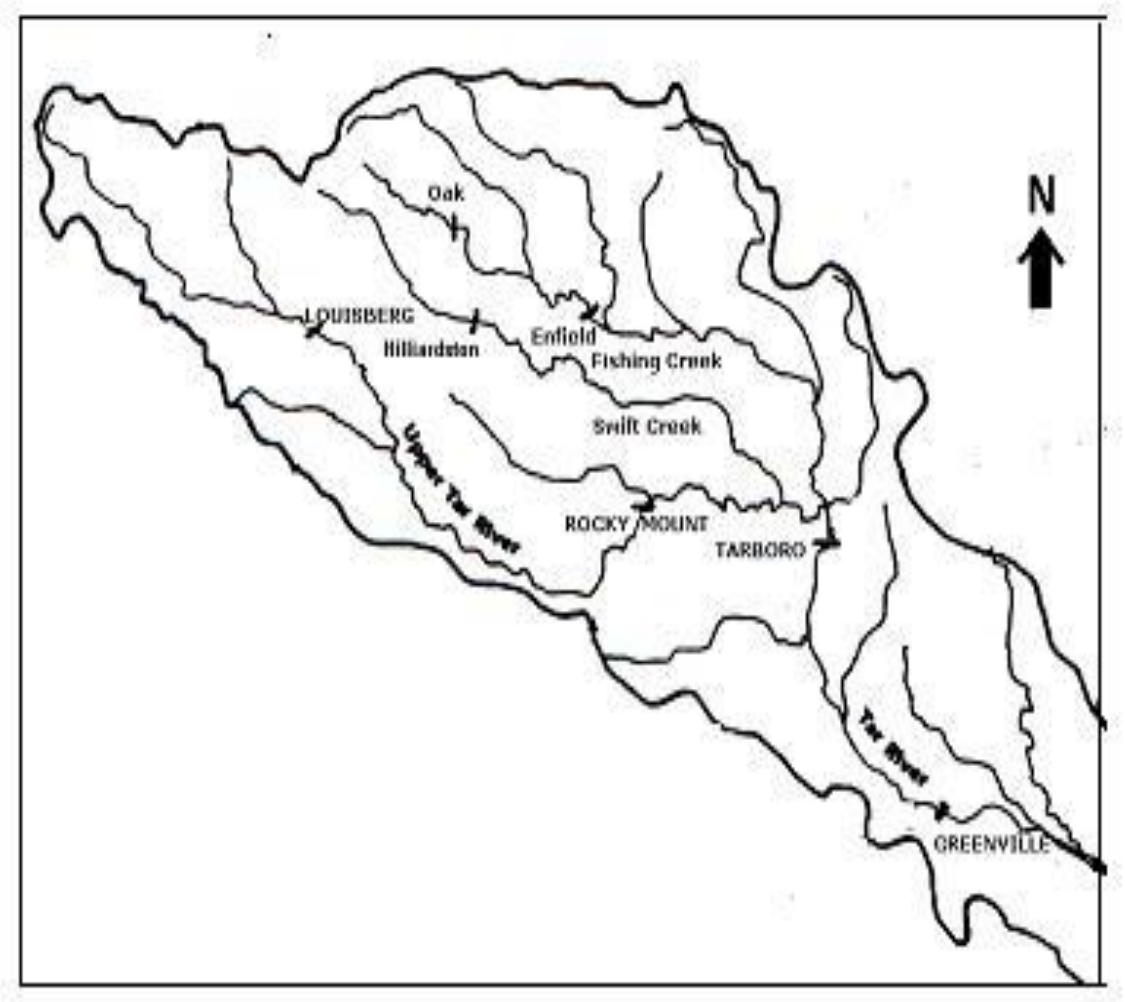

Figure 2 (b). Map of the Study Area in Tar River Basin

\section{Applications}

In the present study, ANFIS and ARIMA models are used to forecast downstream flow depth/discharge in a river system in Barak basin, India. Concurrent flow depths/discharges at time (t-1) at four upstream stations and flow depth/discharge data at time (t) measured for the downstream station are used to develop the ANFIS models for the river system. Water discharge and flow depth data measured at one hour interval are used in this study. Three ANFIS models (i) depth-depth (H-H), (ii) depth-discharge (H-Q) and (iii) discharge-discharge (Q-Q) are used to obtain one hour ahead flood flow forecast for the downstream station in the river system. ANFIS models topology are selected by conducting trials using different number and types of input and output membership functions and the training algorithm. ANFIS model structure with Gaussian input and constant output membership functions with the inputs having two categories has been selected on the basis of minimum RMSE described in Table 1. Different ANFIS models and the data structures 
considered for forecasting common downstream flood flow are as follows:

$$
\begin{aligned}
& H_{F}(t-1), H_{T}(t-1), H_{M}(t-1), H_{B}(t-1) ; H_{B}(t) \\
& H_{F}(t-1), H_{T}(t-1), H_{M}(t-1), Q_{B}(t-1) ; Q_{B}(t) \\
& Q_{F}(t-1), Q_{T}(t-1), Q_{M}(t-1), Q_{B}(t-1) ; Q_{B}(t)
\end{aligned}
$$

where, $H, Q, t$ represent the flow depth, discharge and time respectively. Subscripts $F, T, M, B$ represent respectively upstream stations Phulertal, Tulargram, Matijuri and the downstream station, Badarpurghat.

The above models have four inputs representing concurrent upstream flow depths/flows rates at time (t-1) and downstream flow depth /flow rate at time (t). The forecasting efficiency of the model decreases with the increase in the lead time. The ANFIS model forms are therefore, used to forecast one-hour ahead downstream flows and flow depth. The whole dataset of the flood period is segmented into two categories namely, high flows and low flows; the categories are selected such that peak flow rate has zero membership value in low flow category and minimum flow rate has no or zero membership in the high flow category. Division of four upstream flows into two categories result into a total of sixteen rules in the rule base. The network is trained using a combination of back propagation algorithm to determine the parameters defining the shape of the Gaussian membership function and least-squares estimation technique to estimate the parameters in the output function. To test and verify the results obtained by applying the ANFIS models, common downstream flow depth and discharge values for the river system are also predicted by using the ARIMA models. To apply ARIMA models, flow depth/discharge series is first tested for stationarity by using the time series plot and computing the values for Autocorrelation function (ACF) and Partial Autocorrelation function (PACF). ACF and PACF for the flow depth/discharge series are computed for 16 lags; figure 3 gives the ACF plot for the downstream flow depth/discharge series. The ACF plot shows that lag $1 \mathrm{ACF}$ for the series is close to 1 and the ACF has a linearly decreasing trend. The ACF values computed for both depth and discharge series show similar trend and are presented in Table 3. Since ACF values for depth and discharge series stay close to 1 over many lags, the series are non-stationary and differencing is needed to make the series stationary. In the present study to develop ARIMA models for forecasting flow depth and discharge at the downstream station, only first order differencing is considered. Models with different numbers of autoregressive terms and moving average terms are fitted to the data series by applying SPSS package. BIC and $R^{2}$ value for the ARIMA models with varying $1, \mathrm{~d}$, and q components are computed and compared; in the present study six different ARIMA models were considered for forecasting downstream depth and discharge in the river system. The trial results show that the ARIMA model giving minimum BIC value also yields maximum $\mathrm{R}^{2}$ value. In the present study, $\operatorname{ARIMA}(2,1,2)$ 


\section{Macrothink}

model selected on the basis of minimum BIC and maximum $\mathrm{R}^{2}$ value is found to be the best performing model for forecasting downstream flow depth and discharge in the river system. The ARIMA (2, 1 and 2) model equations used for estimating common downstream depth and discharge in the river system are:

$$
\begin{gathered}
H_{(t)}^{d}=0.004+1.068 H_{(t-1)}^{d}-0.130 H_{(t-2)}^{d}+0.867 \varepsilon_{(t-1)}-0.157 \varepsilon_{(t-2)} \\
Q_{(t)}^{d}=-2.814+1.115 Q_{(t-1)}^{d}-0.180 Q_{(t-2)}^{d}+0.918 \varepsilon_{(t-1)}-0.211 \varepsilon_{(t-2)}
\end{gathered}
$$

BIC and $R^{2}$ values for equation 8 is -7.35 and 0.92 respectively while for equation 9 , the values are 5.014 and 0.84 respectively.

The ARIMA H-model and Q-model represented by Eqn (8) and (9) respectively are used to forecast downstream flow depth and discharge series for the river system. Depth and discharge series predicted by the ANFIS and ARIMA models are given in figure 4 and figure 5. Performances of the ANFIS and ARIMA models are evaluated using statistical criteria: Coefficient of Correlation (CORR), Nash-Sutcliffe model efficiency coefficient (CE), Root Mean Square Error (RMSE) and Mean Absolute Error (MAE). Coefficient of correlation describes how the two data set moves, when $C O R R=1$, it indicates perfect positive linear correlation between the predicted and observed series and the two data sets move in the same direction. Coefficient of Efficiency (CE) is an important statistic describing model fitness. A value of $\mathrm{CE}=1$ indicates perfect model fit while $\mathrm{CE}=0$ represents that the model is as good as the mean model. Whereas RMSE indicates the absolute fit of the model to the data-how close the observed data points are to the model's predicted values. A further validation of the ANFIS model has been done by applying the same model in another river basin (Tar River Basin, USA) to forecast downstream discharge based on upstream discharges. Performances of the ANFIS model applied to Tar River Basin, USA have been presented in Table 2.

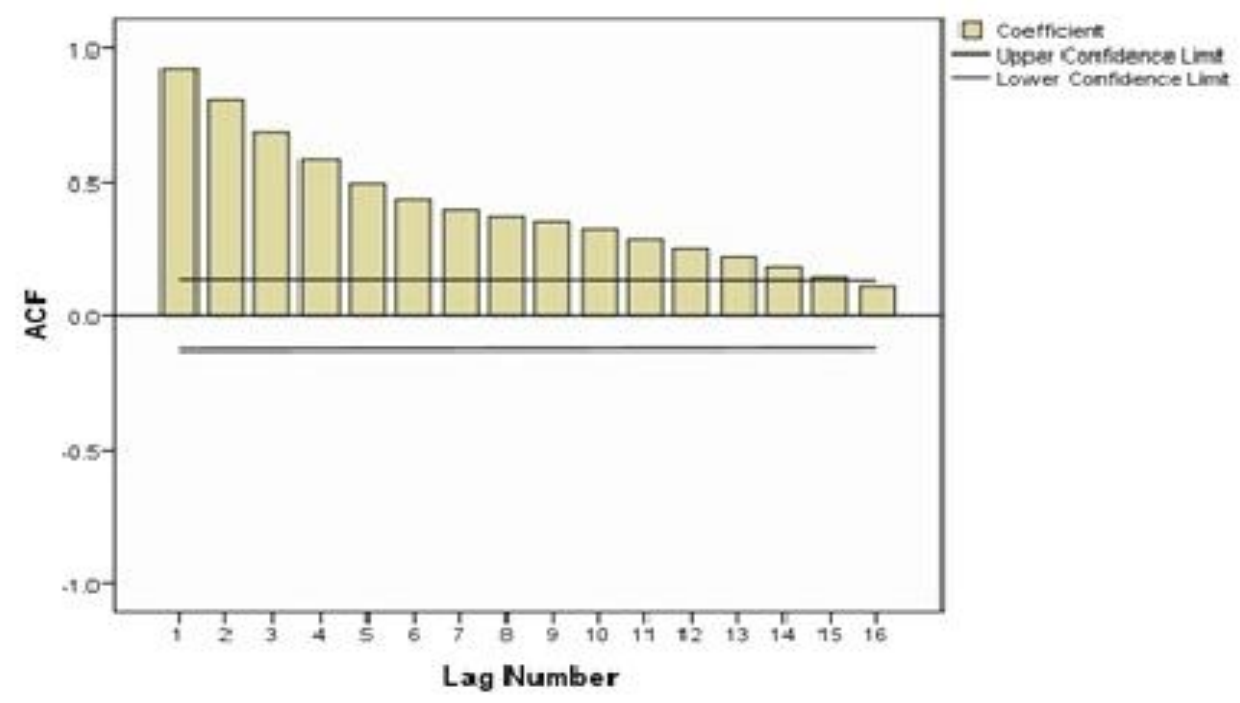

Figure 3. ACF plot for the downstream flow depth/discharge series 


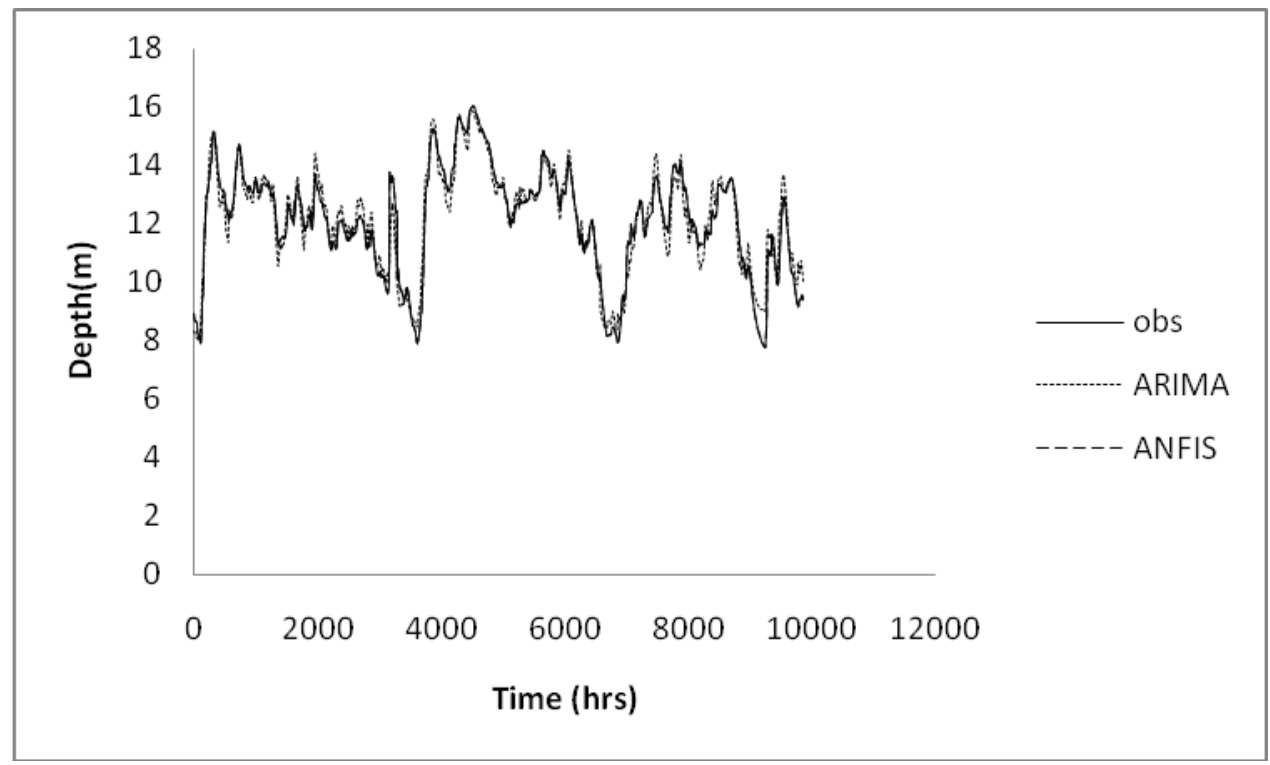

Figure 4. Common downstream flow depths obtained by using ARIMA and ANFIS models

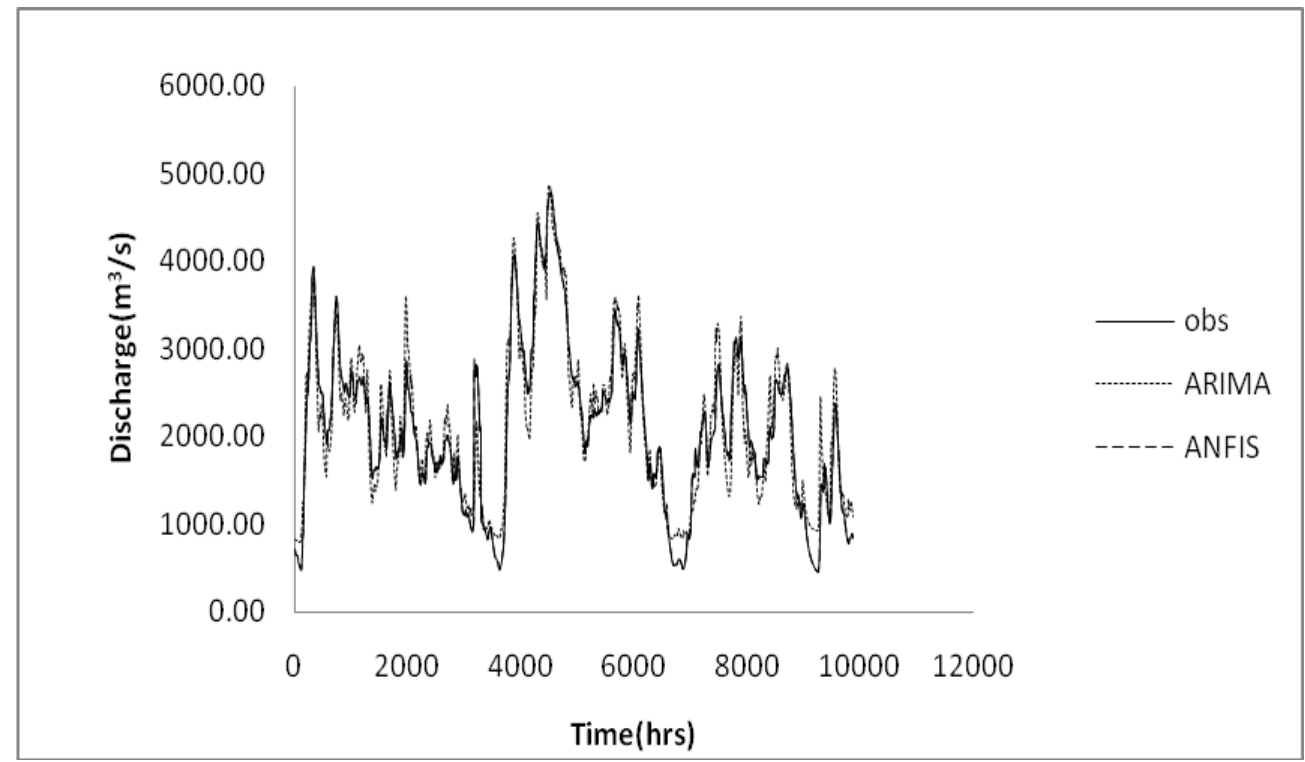

Figure 5. Common downstream discharge in the river system obtained by applying ARIMA and ANFIS models

Table 1. Different standard statistical criteria

\begin{tabular}{|c|c|}
\hline Performance Criteria & Definition \\
\hline CORR & $\frac{\sum_{i=1}^{n}\left(Q_{t}-\bar{Q}_{t}\right)\left(\hat{Q}_{t}-\tilde{Q}_{t}\right)}{\sqrt{\sum_{i=1}^{n}\left(Q_{t}-\bar{Q}_{t}\right)^{2} \sqrt{\sum_{i=1}^{n}\left(\hat{Q}_{t}-\tilde{Q}_{t}\right)^{2}}}}$ \\
\hline
\end{tabular}




\begin{tabular}{|c|c|}
\hline RMSE & $\sqrt{\frac{\sum_{t=1}^{n}\left(\hat{Q}_{t}-Q_{t}\right)^{2}}{n}}$ \\
\hline CE & {$\left[\begin{array}{c}\left.\frac{\sum_{t=1}^{n}\left(\hat{Q}_{t}-Q_{t}\right)^{2}}{\sum_{t=1}^{n}\left(Q_{t}-\bar{Q}\right)^{2}}\right] \\
\hline \text { MAE }\end{array}\right.$} \\
\hline & $\frac{1}{n} \sum_{t=1}^{n}\left|\hat{Q}_{t}-Q_{t}\right|$ \\
\hline
\end{tabular}

where $Q_{t}=$ observed value at time $\mathrm{t}, \hat{Q}_{t}=$ modeled value at time $\mathrm{t}, \bar{Q}_{t}=$ mean of the observed data, and $\tilde{Q}_{t}=$ mean of the modeled data, $\mathrm{n}=$ total number of observations

Table 2. ANFIS and ARIMA models performances for testing period.

\begin{tabular}{|c|c|c|c|c|c|c|}
\hline \multirow{2}{*}{$\begin{array}{l}\text { RIVER } \\
\text { BASINS }\end{array}$} & \multirow{2}{*}{$\begin{array}{l}\text { Performance } \\
\text { Measures }\end{array}$} & \multicolumn{3}{|c|}{ ANFIS MODEL } & \multicolumn{2}{|c|}{ ARIMA MODEL } \\
\hline & & $\begin{array}{c}\mathrm{H}-\mathrm{H} \\
\operatorname{model}(\mathrm{m})\end{array}$ & $\begin{array}{c}\mathrm{H}-\mathrm{Q} \\
\text { model }\end{array}$ & $\begin{array}{c}\mathrm{Q}-\mathrm{Q} \\
\operatorname{model}\left(\mathrm{m}^{3} / \mathrm{s}\right)\end{array}$ & H-model & Q-model \\
\hline \multirow{4}{*}{$\begin{array}{l}\text { BARAK } \\
\text { BASIN }\end{array}$} & RMSE & 0.538 & 0.743 & 0.930 & 0.923 & 0.983 \\
\hline & $\mathrm{CE}$ & 0.975 & 0.885 & 0.82 & 0.90 & 0.81 \\
\hline & MAE & 0.518 & 0.721 & 0.904 & 0.918 & 0.961 \\
\hline & CORR & 0.99 & 0.924 & 0.860 & 0.925 & 0.83 \\
\hline \multirow{4}{*}{$\begin{array}{l}\text { TAR } \\
\text { BASIN }\end{array}$} & RMSE & & & 0.768 & & \\
\hline & $\mathrm{CE}$ & & & 0.924 & & \\
\hline & MAE & & & 0.843 & & \\
\hline & CORR & & & 0.967 & & \\
\hline
\end{tabular}


Table 3. Autocorrelation values for flow depth/discharge series.

\begin{tabular}{|l|l|l|l|l|l|}
\hline \multirow{2}{*}{ Lag } & \multirow{2}{*}{$\begin{array}{l}\text { Autocorrelati } \\
\text { on }\end{array}$} & Std. Error & \multicolumn{3}{|l|}{ Vox-Ljung Statistic } \\
\cline { 4 - 6 } & 1.000 & .010 & $9.857 \mathrm{E} 3$ & 1 & .000 \\
\hline 1 & .999 & .010 & $1.970 \mathrm{E} 4$ & 2 & .000 \\
\hline 3 & .998 & .010 & $2.954 \mathrm{E} 4$ & 3 & .000 \\
\hline 4 & .998 & .010 & $3.936 \mathrm{E} 4$ & 4 & .000 \\
\hline 5 & .997 & .010 & $4.916 \mathrm{E} 4$ & 5 & .000 \\
\hline 6 & .996 & .010 & $5.895 \mathrm{E} 4$ & 6 & .000 \\
\hline 7 & .995 & .010 & $6.871 \mathrm{E} 4$ & 7 & .000 \\
\hline 8 & .993 & .010 & $7.845 \mathrm{E} 4$ & 8 & .000 \\
\hline 9 & .992 & .010 & $8.817 \mathrm{E} 4$ & 9 & .000 \\
\hline 10 & .991 & .010 & $9.786 \mathrm{E} 4$ & 10 & .000 \\
\hline 11 & .989 & .010 & $1.075 \mathrm{E} 5$ & 11 & .000 \\
\hline 12 & .988 & .010 & $1.172 \mathrm{E} 5$ & 12 & .000 \\
\hline 13 & .986 & .010 & $1.268 \mathrm{E} 5$ & 13 & .000 \\
\hline 14 & .985 & .010 & $1.363 \mathrm{E} 5$ & 14 & .000 \\
\hline 15 & .983 & .010 & $1.459 \mathrm{E} 5$ & 15 & .000 \\
\hline 16 & .981 & .010 & $1.554 \mathrm{E} 5$ & 16 & .000 \\
\hline
\end{tabular}

Performances of different ANFIS and ARIMA models evaluated in terms of statistical criteria described in Table 1 are listed in Table 2. From the results presented in Table 2, it can be found that performance statistics CE and CORR values for ARIMA and ANFIS models in estimating downstream flow depths are better than the corresponding discharge estimation model. Also, it can be found that performances of the ANFIS depth-depth model are better than all other models considered in the study. Better performances by the depth estimation models can be attributed to the fact that the flow depths being measured data are more accurate compared to the discharge series that are obtained using measured depth data by applying rating curve for a station. The CE and CORR values for different ANFIS models are found to be more than 0.82 and 0.86 respectively while CE and CORR values obtained for the ARIMA models are more than 0.81 and 0.83 respectively. Considering that CE values for the multiple inputs ANFIS models are more than 0.82, performances of the ANFIS models 
may be considered satisfactory. Comparison of ANFIS and ARIMA models results show better performances by the ANFIS model in forecasting common downstream flow depths and discharges in the studied river system. To further validate application of ANFIS model for a river system the model is applied to Tar River Basin, USA for forecasting two-hour ahead downstream discharge on the basis of four upstream discharges. The upstream discharges are divided into three categories and Gaussian membership is selected for all the inputs. The model results are also listed in Table 2. Results given in Table 2 show that ANFIS model perform satisfactorily in predicting flow rate at the downstream station "Tarboro" on the basis of three upstream flows in the Tar River Basin. The study demonstrates that the ANFIS model can be effectively used to forecast downstream flow rates in a river system using multiple upstream flows

\section{Conclusions}

This paper presents the application of a data-driven model, ANFIS in forecasting flood flows in a river system. ANFIS is a powerful modeling technique and it works on a set of linguistic if-then rules. It can handle imprecision and uncertainty present in the model and the data structure and thus can be used for real-time applications. In the present study, first order Takagi-Sugeno fuzzy inference system is used to forecast one-hour ahead downstream flow depths and discharges based on multiple upstream flows/flow depths. For this purpose, different depth-discharge forecasting models given by Eqs (5), (6) \& (7) have been applied to the study area. Multiple inputs-single output ANFIS models are used to forecast common downstream flow rates and flow depths in a river system in Barak basin, India. A set of 16 rules arising out of four upstream inflows being considered for the river system, each with two categories are used to estimate common downstream flood flow. ARIMA is a standard time series prediction model and is used to test and verify applications of the multiple inflows ANFIS model. ARIMA models with appropriate $1, \mathrm{~d}$, and q parameters are selected on the basis of minimum BIC and maximum $\mathrm{R}^{2}$ values. One hour ahead forecasts of downstream flow depths/discharge obtained by applying ARIMA models are compared with the results obtained from the ANFIS models. Results show that models based on flow depth data forecast flood more accurately than the models using discharge data. Comparison of the ANFIS model performances with ARIMA models indicates that results of the multiple inflows ANFIS model closely follow the results of the ARIMA model developed. Application of the ANFIS model is further tested by using it in Tar River basin, USA to forecast downstream discharge using multiple inflows in the basin. Results of the ANFIS model applied to the Tar River Basin are also satisfactory in terms of all the statistical criteria used. The ANFIS model thus, can efficiently map multiple inputs to a single output and is useful for simulating/forecasting common downstream outflow on the basis of several upstream flows.

\section{Acknowledgement}

The authors would like to thank Central Water Commission, Shillong for supplying the necessary data. The authors are also highly thankful to DST (SERC) and Indian Statistical Institute, Kolkata for giving full assistance in carrying out the study. 


\section{References}

Bazartseren, B., Hildebrandt, G., \& Holz, K. P. (2003). Short-term water level prediction using neural network and neuro-fuzzy approach. Neurocomputing, 55(3-4), 439-450. http://dx.doi.org/10.1016/S0925-2312 (03)00388-6.

Box, G.E.P \& Jenkins, G.M. (1976). Time-series Analysis: Forecasting and Control. Holden Day Inc. San Francisco, CA. 575.

Chau, K.W., \& Lee, J.H.W. (1991a). Mathematical modeling of Shing Mun River Network. Advances of Water Resources, 14(3), 106-112.

Chau, K.W., \& Lee, J.H.W. (1991b). A microcomputer model for flood prediction with applications. Micro computers in Civil Engineering, 6(2), 109-121. http://dx.doi.org/10.1111/j.1467-8667.1991.tb00181.x.

Chen, S.H., Lin, Y.H., Chang, L.C., \& Chang, F.J. (2006). The strategy of building a flood forecast model by neuro-fuzzy network. Hydrological Processes, 20, 1525-1540. http://dx.doi.org/10.1002/hyp.5942.

Chidthong, Y., Tanaka, H., \& Supharatid, S. (2009). Developing a hybrid multi-model for peak flood forecasting. Hydrological Processes, 23(12), 1725-1738. http://dx.doi.org/10.1002/hyp.7307

Dawson, C.W., \& Wilby, R. (1998). An artificial neural network approach to rainfall-runoff modeling. Hydrological Sciences Journal, 43(1), 47-66.

El-Shafie., Taha, M.R., \& Noureldin, A. (2007). A neuro-fuzzy model for inflow forecasting of the Nile River at Aswan high dam. Water Resources Management, 21, 533-556. http://dx.doi.org/10.1007/s11269-006-9027-1.

Feyen, L., Vazquez, R., Christiaens, K., Sels, O., \& Feyen, J. (2000). Application of a distributed physically-based hydrological model to a medium size catchment. Hydrology and Earth System Sciences, 4(1), 47-63. http://dx.doi.org/10.5194/hess-4-47-2000

Gupta, K., V.H. \& Sorroshian (1995). Artificial neural network modeling of the rainfall-runoff process. Water Resources Research, 31(10), 2517-2530.

Jacquin, A.P., \& Shamseldin, A.Y. (2006). Development of rainfall-runoff models using Takagi-Sugeno fuzzy inference systems. Journal of Hydrology, 329, 154-173. http://dx.doi.org/10.1016/j.jhydrol.2006.02.009

Jang, J.S.R. (1993). ANFIS: adaptive- network based fuzzy inference system. IEEE Transactions on Systems, Man and Cybernetics, 23(3), 665-685.

Jang, J.S.R., \& Sun, C.T. (1997). Neuro-fuzzy and soft computing: A computational Approach to Learning and Machine Intelligence. Prentice Hall, Englewood Cliffs, New jersey. 
Karl, A.K., \& Lohani, A.K. (2010). Development of flood forecasting system using Statistical and ANN Techniques in the downstream catchment of Mahanadi Basin, India. Journal of Water Resource and Protection, 2(10), 880-887. http://dx.doi.org/10.4236/jwarp.2010.210105

Kitanidis, P.K., \& Bras, R.L. (2010). Real-time forecasting with a conceptual hydrological model. Water Resources Research, 16(6), 1034-1044. http://dx.doi.org/10.1029/WR016i006p01034

Liong, S.Y., Lim, W.H., \& Paudyal, G. (2000). River stage forecasting in Bangladesh: Neural Network approach. Journal of Computing in Civil Engineering, 14(1), 1-8.

Maier, H.R., \& Dandy, G.C. (1997). Determining inputs for neural network models of multivariate time-series. Micro computers in Civil Engineering, 12, 353-368. http://dx.doi.org/10.1111/0885-9507.00069.

Martins Otache, Y., Sadeeq, M.A., \& Ahaneku, I.E. (2011). ARMA Modeling of Benue River Flow Dynamics: Comparative Study of PAR Model. Open Journal of Modern Hydrology, 1, 1-9. http://dx.doi.org/10.4236/ojmh.2011.11001

Masmoudi, M., \& Habaieb, H. (1993). The Performance of some Real-time statistical flood-forecasting models seen through Multicriteria Analysis. Water Resources Management, 7, 57-67.

Nayak, P.C., Sudheer, K.P., Rangan, D.M., \& Ramasastri, K.S. (2005b). Short-term flood forecasting with a neuro-fuzzy model. Water Resources Research, 41, W04004. http://dx.doi.org/10.1029/2004WR003562.

Rosenberg, E.A., Wood, A.W., \& Steinemann, A.C. (2011). Statistical applications of physically based hydrological models to seasonal streamflow forecasts. Water Resources Research, 47(3). http://dx.doi.org/10.1029/2010WR010101

Tokar, A.S., \& Johnson, P.A. (1999). Rainfall-runoff modeling using artificial neural networks. Journal of Hydrologic Engineering, 4(3), 232-239.

Valipour, M., Banihabib, M.E., \& Behbahani, S.R. (2012). Parameters Estimate of Autoregressive Moving Average and Auto-regressive Integrated Moving Average Models and Compare their Ability for Inflow Forecasting. Journal of Mathematics and Statistics, 8(3), 330-338.

Wagener, T., Boyle, D.P., Lees, M.J., Wheater, H.S., Gupta, H.V. \& Sorooshian, S. (2001). A framework for development and application of hydrological models. Hydrology and Earth System Sciences, 5(1), 13-26. http://dx.doi.org/10.5194/hess-5-13-2001

\section{Copyright Disclaimer}

Copyright reserved by the author(s).

This article is an open-access article distributed under the terms and conditions of the Creative Commons Attribution license (http://creativecommons.org/licenses/by/3.0/). 